Case study

\title{
EXCESS OF PLASMA CELLS WITH PSEUDO-GAUCHER CELLS IN A CASE OF TUBERCULOSIS - A CASE REPORT
}

\author{
Palta A, Dhiman P, Ram J \\ Department of Pathology \& Medicine, Govt. Medical College \& Hospital , Chandigarh, India.
}

\begin{abstract}
This report describes a case of 50 year old woman fever and bony pains with lytic lesion in skull. A polyclonal band was seen in y region on serum electrophoresis. Bone marrow examination showed excess of plasma cells along with many Pseudo- Gaucher cells. The diagnosis of chronic inflammatory reaction was made. Although stain for AFB was negative, the patient responded to antitubercular treatment. The presence of pseudo-gaucher cells along with plasmacytosis is a rare finding in tuberculosis.
\end{abstract}

Key words: Tuberculosis, Pseudogaucher Cell

\section{INTRODUCTION}

Tuberculosis, one of the oldest diseases known to affect humans, is a major cause of death worldwide. ${ }^{1}$ According to World Health Organization (WHO), there were an estimated 8.8 million incident cases of TB globally in 2010, 1.1 million deaths among HIV-negative cases of TB and an additional 0.35 million deaths among people who were HIVpositive. India alone accounted for an estimated one quarter $(26 \%)$ of all TB cases worldwide with 2.0-2.5 million new cases of TB in 2010. ${ }^{2}$

A variety of haematological alterations ranging from various cytopenias to leukaemoid reaction and even frank leukemia in association with tuberculosis have been reported. ${ }^{3}$ It can present with anemia, neutrophilic leucocytosis, monocytosis or lymphocytosis. Some patients may show hypoplasia of one or more cell lines, associated with anemia, neutropenia and thrombocytopenia. ${ }^{4}$ Here we describe a case of tuberculosis in which bone marrow revealed cluster of pseudo-Gaucher cells with plasma cells making it difficult to exclude the diagnosis of multiple myeloma.

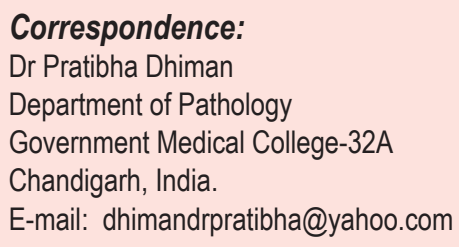

\section{CASE REPORT}

A 50-year old female presented with complaints of fever, cough and bony pains since 5 weeks to our hospital. On physical examination no lymphadenopathy and hepatosplenomegaly noted. The hemogram showed anemia with a hemoglobin of $5.3 \mathrm{~g} / \mathrm{dl}$, high TLC of $14,000 / \mu \mathrm{l}$ with DLC of $\mathrm{P}_{83}$ $L_{13} M_{02} E_{02}$ and platelet count of $2.4 \times 10^{5 /} \mu \mathrm{l}$. ESR was $60 \mathrm{~mm} / \mathrm{hr}$. Both blood \& urine cultures were negative. Skeletal survey showed lytic lesion in skull. CT scan revealed focal cystic lesion with fibrotic change in upper zone of right lung along with effusion. CT abdomen did not show any abnormality. Serum electrophoresis for $M$ band showed a polyclonal band in $\mathrm{y}$ region (Figure 1). Urine for Bence jones proteins (BJP) was negative. Serology for HIV, HBsAg and antiHCV were negative. Bone marrow aspiration and trephine biopsy were done for persistent anemia and pyrexia of unknown origin.

The bone marrow examination showed hypercellular marrow with $23 \%$ plasma cells along with many binucleate forms (Figure 2). Many scattered large cells with small and dense nuclei with abundant amount of foamy granular cytoplasm were identified. Biopsy also showed collection of these histiocytes with reticular cytoplasm (Figure 3). These cells were negative for Perl's stain conforming to the morphology of Pseudo-gaucher 


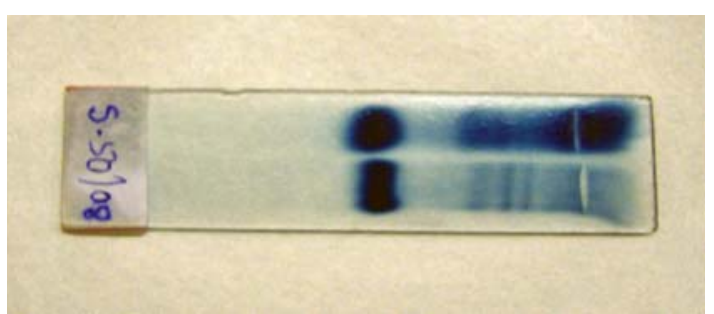

Figure 1: Serum electrophoresis showing polyclonal band in gamma globulin region

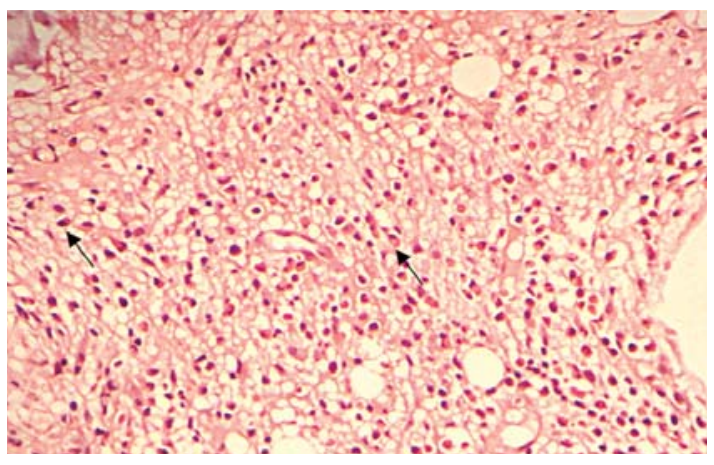

Figure 2: Trephine biopsy showing excess of plasma cells (Arrow head) (H\&Estain,400X)

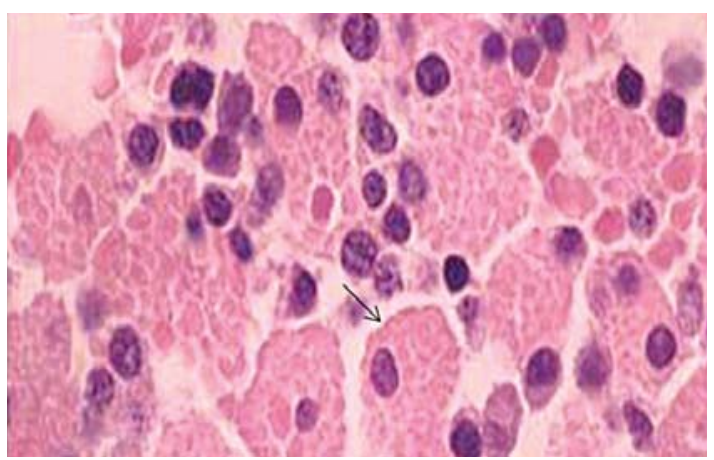

Figure 3: Trephine biopsy showing Pseudo-Gaucher cells (Arrow head) (H\&Estain,1000X)

cells. There was focal area of fibrosis (reticulin stain) (Figure 4). Although stain for AFB was negative and the count of plasma cells was in range of criteria for multiple myeloma, in view of polyclonal band in y region and urine negative for BJP ,a possibility of chronic inflammatory reaction was suggested. As per data, AFB microscopy has $40-60 \%$ sensitivity. ${ }^{1}$ The examination of pleural fluid show high protein level along with high ADA and increased lymphocytes. Patient was given ATT. Patient became afebrile and follow up hemogram after one month of treatment revealed hemoglobin of $8.2 \mathrm{~g} / \mathrm{dl}$ with single whole blood transfusion which she has received before starting ATT.

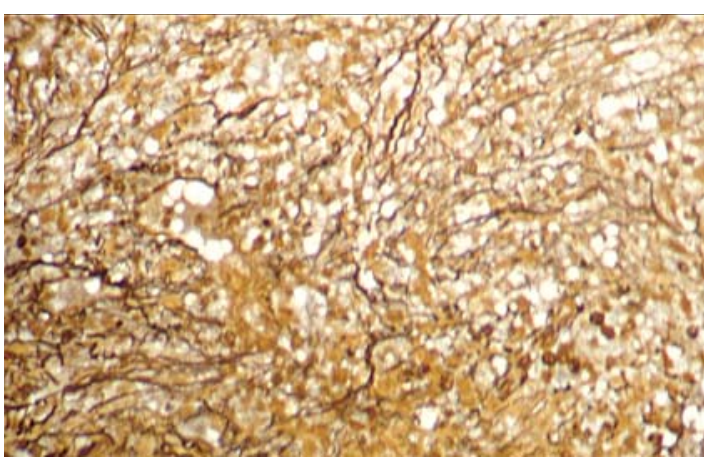

Figure 4: Trephine biopsy showing focal fibrosis (Reticulin stain, 400X)

\section{DISCUSSION}

We, here present a case of tuberculosis in immunocompetent patient associated with pseudogaucher cells and an excess of plasma cells. Typical Gaucher cells have a characterstic wrinkled tissue paper appearance of the cytoplasm as a result of deposition of glucocerebroside. These cells can be upto $60 \mu \mathrm{m}$ in diameter with fibrillary structures in the cytoplasm. ${ }^{5}$ In the presence of cytopenias, hepatosplenomegaly, and typical Gaucher cells in the bone marrow, the diagnosis of Gaucher disease is made. In our case patient was normal before the presentation of tuberculosis. Bone marrow cells with morphological characterstics similar to Gaucher cells have been rarely described in chronic myeloid leukemia, Hodgkin's lymphoma, thalassemia and multiple myeloma. ${ }^{6}$

Solis et al reported the first case of pseudo-gaucher cells in Mycobacterium avium - intercellulare infection in HIV infected patient. They noted massive infiltration of lamina propria of the bronchial mucosa \& bone marrow with foamy histiocytes. ${ }^{7}$ Later link et al noted another case of tuberculosis with pseudo-gaucher cells in bone marrow, lymph nodes, spleen \& lungs. This patient had pulmonary tuberculosis and the HIV status was unknown. In this case stain for AFB and Periodic acid Schiff staining were negative. ${ }^{8}$

In our case also these cells were negative for Periodic acid Schiff and Perl's stain. Based on immunologic studies, the cell of origin of the pseudo-Gaucher cell appears to be the monocyte. 
On electron microscopy, Gaucher cells contain tubular cytoplasmic inclusions, which are absent in pseudo-Gaucher cells. $^{6}$

Reactive plasmacytosis have been described in patients with liver disease, chronic infections, connective tissue diseases and carcinoma.$^{9} \mathrm{An}$ excess of plasma cells have been described in tuberculosis but upto the extent of $23 \%$ have not been described in the literature till date to the best of our knowledge.

\section{CONCLUSION}

An excess of plasma cells along with pseudoGaucher cells in bone marrow, should be dealt with caution. Pseudo-Gaucher cells might be the morphological hallmark of mycobacterial infection in immunodeficiency but otherwise also AFB stain should be performed. Before thinking on the lines of Multiple myeloma possibility of tuberculosis should be considered and patient should be worked up accordingly.

\section{REFERENCES}

1. Raviglione MC, Brien RJ. Tuberculosis. Fauci AS, Braunwald E, Kasper DL, editors. Harrison's Principles of Internal Medicine. $17^{\text {th }}$ ed. New York: McGraw Hill. 2008;1006-7.
2. Global Tuberculosis Control: The burden of disease caused by TB; 2011. WHO Technical Report.

3. Chandra, J., Marwaha, R.K., et al. Pancytopenia and Leukemoid Reactions in Tuberculosis. Indian J. Paed; 1986;53:665.

4. Fleming AF, De Silva PS. Hematological Diseases in Tropics. Cook GC, Manson M, Zumla A, editors. Manson's Tropical Diseases. $22^{\text {nd }}$ ed. Edinburgh: Saunders. 2008;:211-12.

5. Dunn P, Kuo M-C, Sun C-F. Pseudo-Gaucher cells in mycobacterial infection: A Report of Two Cases. J Clin Pathol. 2005;58:1113-4.

6. Shenjere P, Roy A, Banerjee S. Pseudo-Gaucher Cells in Multiple Myeloma. Int. J Surg. Pathol. 2008:16:176-9.

7. Solis OG, Belmonte AH, Ramaswamy G, et al. Pseudogaucher Cells in Mycobacterium Avium Intracellulare Infection in Acquired Immune Deficiency Syndrome (AIDS). Am J Clin Pathol. 1986;85:233-5.

8. Links TP, Karrenbeld A, Steensma JT, et al. Fatal respiratory failure caused by pulmonary infiltration by Pseudo-Gaucher cells. Chest 1992;101:265-6.

9. Dispenzieri A, Gertz MA, Therneau TM, et al. Retrospective cohort study of 148 patients with polyclonal gammopathy. Mayo Clin Proc 2001;76:476-487. 